\title{
Improvement of a Lightweight Power Assist Suit for Nursing Care
}

\author{
Chiharu Ishii and Kotaro Yoshida
}

\begin{abstract}
In this paper, for the purpose of practical use of the power assist suit, the overalls type power assist suit developed in our previous study was improved. The knee pad type power assist suit termed "Cool Vest" was newly developed, and verification experiments were carried out. By wearing the developed assist suit, the muscular load decreased $46 \%$ at the maximum in the case of lifting and taking down the $30 \mathrm{~kg}$ object and decreased $43 \%$ at the maximum in the case of transferring the $20 \mathrm{~kg}$ object by turning around. In addition, air supplying method to the artificial muscle was also improved. An air recycling system and an air generation system were proposed, and evaluation experiments were executed. As results, the number of times which can be used for assisting the transfer work increased from 5 times to 7 times by using these air supplying systems.
\end{abstract}

Index Terms-Power assist suit, artificial muscle, cool vest, air supplying system.

\section{INTRODUCTION}

Nowadays, Japan has reached to the super-aging society. Therefore, demand for caregivers who take care of elderly people has been increasing at care centers and nursing homes. In nursing care, when the caregiver performs transfer work, he/she lifts the elderly people from the bed with the slouchy posture, and sits the elderly people on the wheelchair. At that time, a big burden is added to the caregiver's waist. Therefore, many of caregivers have lumbago. Hence, an equipment that reduces the burden of the caregiver's waist is needed. In such a background, various types of power assist suit have been developed extensively, so far.

The actuator of the power assist suit is divided into two types, namely electric motor and pneumatic actuator. The Hybrid Assistive Limb (HAL) [1] is a power assist suit which recognizes motion of the wearer by electromyogram, and supports wearer's motion by motor actuation. The AWN-03 [2] is a wearable robot to reduce the burden on the body by motor actuation when lifting and lowering heavy objects.

On the other hand, a power assist suit which senses motion of the wearer by the muscle hardness sensor was developed to support holding up and down heavy objects using the pneumatic rotary actuators [3]. The Muscle Suit [4] employed McKibben-type pneumatic artificial muscle as an actuator, and when the wearer lifts heavy objects, the muscle suit assists a muscular force of the wearer.

Manuscript received December 20, 2018; revised February 19, 2019.

Chiharu Ishii is with the Department of Mechanical Engineering, Hosei University, Tokyo, Japan (e-mail: c-ishii@hosei.ac.jp).

Kotaro Yoshida is with the Graduate School of Science and Engineering, Hosei University, Tokyo, Japan (e-mail koutaro.yosida.5y@stu.hosei.ac.jp).

DOI: $10.7763 /$ IJET.2019.V11.1157
Nowadays, commercially available wearable devices are produced by many companies in various countries. Ekso Bionics [5] in USA produces the EksoVest which can reduce fatigue for overhead work. German Bionic [6] in Germany produces the Cray X which assists the wearer's waist when lifting heavy objects. Hyundai Rotem [7] in South Korea produces the H-CEX for knee assist, the RMX for waist assist and the H-VEX for shoulder assist.

However, these power assist suits are exoskeleton, and have the following problems; 1) The equipment is heavy and expensive. 2) It takes long time for attachment and detachment of the suit.

In such a back ground, a semi-endoskeleton-type waist assist AB-wear suit was developed in [8], which is actuated by two types of actuators, namely straight-fibertype artificial muscles and a balloon actuator. Also, a light weight power assist wear which uses two types of pneumatic soft actuators, namely balloon and circular actuators, was developed in [9] to reduce a physical burden caused by heavy equipment.

While, a passive power assist supporter utilizing the elastic force of elastic belts called Smart Suit [10] was developed to reduce fatigue and load of the wearer. The Smart Suit is compact and lightweight, but its assist force is not enough as compared with the power assist suits.

Therefore, we have developed a lightweight and low cost power assist suit for nursing care [11], in which McKibben-type pneumatic artificial muscle was employed as an actuator and overalls was used to simplify putting on and taking off the suit. The developed power assist suit is endoskeleton, and is compact, lightweight and has enough assist force.

However, it has the following problems; 1) Since the overalls is used, the developed power assist suit does not breathe well. 2) In fullness of 1 time of the compressed air to the air tank attached to the assist suit, the number of times which can be used for assistance is a few.

Therefore, in this paper, for the purpose of practical use of the power assist suit, our previously developed power assist suit was improved as follows. First, the assist suit for nursing care which is separable into outerwear (vest) and knee pads was built. Then, verification experiments were carried out and the results showed that the muscular load decreased by wearing the built assist suit.

Second, in order to increase the number of times which can be used for assistance, air supplying method to the artificial muscle was improved. It should be noted that there are few literatures which discuss the power source of the pneumatic artificial muscle to enhance energy efficiency. A novel hybrid pneumatic power source was proposed in [12] for developing a portable pneumatic source. 
In this paper, an air recycling system and an air generation system were proposed as air supplying system. Then, evaluation experiments were executed. As results, the number of times which can be used for assistance increased by using these air supplying systems.

\section{KNEE PAD Type Assist SuIT "COOL Vest"}

\section{A. Overview of the Knee Pad Type Assist Suit}

The developed knee pad type assist suit is shown in Fig. 1, which was termed "Cool Vest". The Cool Vest is composed of vest, pneumatic artificial muscle, knee pad, air tank and thigh belt, and is separable into vest and knee pads with thigh belt. The breathability of the assist suit was improved by adopting the vest. Two McKibben-type artificial muscles are attached to the back of the assist suit by V-shape. Gross weight of the Cool Vest is less than $4 \mathrm{~kg}$.

Operation principle of the Cool Vest is explained as follows. First of all, the air tanks must be filled with the compressed air using the compressor. When the compressed air is supplied to the artificial muscles from the air tanks, the artificial muscles shrink and generate large contractile force. The artificial muscles and the knee pads are connected by the thigh belt. From this, the contractile force generated by the artificial muscles turns into force which pulls the upper part of the body. This force assists the caregiver to lift the care-receiver.

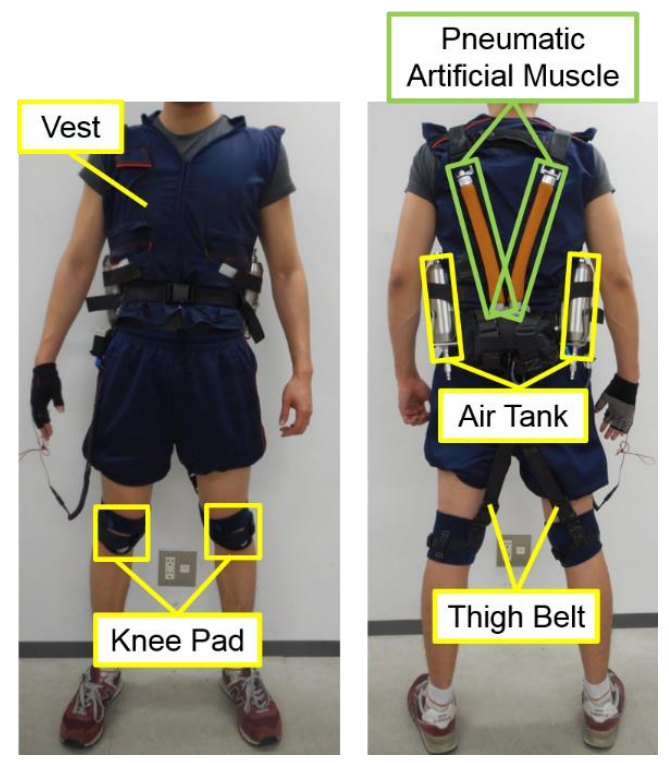

Fig. 1. Knee pad type assist suit "cool vest".

\section{B. Pneumatic Artificial Muscle}

As an actuator of the Cool Vest, McKibben-type pneumatic artificial muscle is used. There are two sizes of the artificial muscles, namely L-size and S-size. The specifications of the artificial muscle are shown in Table I.

\section{Air Tank}

Two air tanks with each capacity of $750 \mathrm{ml}$ are attached to the wearer's waist, and they are exchangeable when the compressed air is used up. In the case where the air compressor is used as the source of supply of the compressed air, caregiver's area of activity is restricted to neighborhood of the compressor. In contrast, in the case where the air tank is used as the source of supply of the compressed air, caregiver's area of activity is expanded. However, the number of times which can be used for assisting the transfer work is restricted instead.

TABLE I: SPECIFICATIONS OF THE ARTIFICIAL MUSCLE

\begin{tabular}{|c|c|}
\hline Weight/[g] & Less than 137 \\
\hline Power capacity $[\mathrm{N}]$ & $\begin{array}{c}\text { A maximum of } 1800 \text { (when } 0.5 \mathrm{MPa} \\
\text { compressed air was supplied.) }\end{array}$ \\
\hline \multirow{2}{*}{ Entire length $[\mathrm{mm}]$} & A maximum of 330 (for L-size) \\
\cline { 2 - 2 } & A maximum of 280 (for S-size) \\
\hline Shrinkage $[\mathrm{mm}]$ & A maximum of 80 (for L-size) \\
\cline { 2 - 2 } & A maximum of 50 (for S-size) \\
\hline Diameter & $\varphi 50$ (on pressurizing) \\
\hline
\end{tabular}

\section{Switch}

The glove-type tact switch and the push switch attached to the side of the index finger shown in Fig. 2 were made so that the switch can be pushed easily when performing transfer work. The compressed air is supplied to the artificial muscles by pushing the switch once. The air supplied to the artificial muscles is released by a long pressing of the switch.

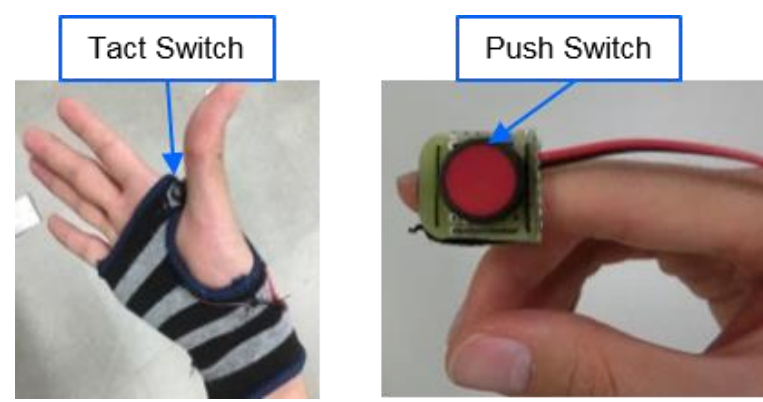

Fig. 2. Glove-type tact switch (left) and Push switch (right)

\section{VERIFICATION EXPERIMENTS}

In order to verify an assist effect of the Cool Vest, 2 kinds of experiments were carried out. Then, the assist effect was evaluated by reduction rate of the burdens of the muscles obtained by the integrated electromyogram (IEMG).

\section{A. Integrated Electromyogram (IEMG)}

It is well known that the integrated electromyogram (IEMG) implies the activity of the muscle. Thus, the IEMG was used for evaluation of the assist effect. The IEMG is an integration of the rectified surface electromyogram (SEMG) signal, namely the mathematical integral of the absolute value of the SEMG signal, which is given as follows:

$$
I E M G=\int_{t-\Delta t}^{t}|S E M G| d t
$$

where SEMG is the SEMG signal of the muscle of the measurement part, and $\Delta t$ is the interval of the integration. In this study, the SEMG was measured by sampling frequency $1 \mathrm{kHz}$, and the interval of the integration $\Delta t$ in equation (1) was selected as $0.256 \mathrm{~s}$. 


\section{B. Experimental Method}

Assuming the actual transfer work in nursing care, the following two experiments were executed.

1) Experiment of lifting the heavy object

2) Experiment of transferring the heavy object by turning around

Experiments were carried out for a healthy subject in his $20 \mathrm{~s}$, and each experiment was executed under the state of wearing and un-wearing the Cool Vest. In addition, for the experiment 1), the experiment under the state of wearing the overalls type assist suit developed in the previous study was also executed.

\section{1) Experiment of lifting the heavy object}

Along the 4 steps shown in Fig. 3, the subject lifted and took down the $30 \mathrm{~kg}$ heavy object in 10 seconds. State A is the initial posture where the subject stood in front of the heavy object. State B is the stand-by posture where the subject held the heavy object after around 4 seconds from the experiment start. State $C$ is the state where the subject lifted the heavy object. State D is the state where the subject took down the heavy object after around 7 seconds from the experiment start.

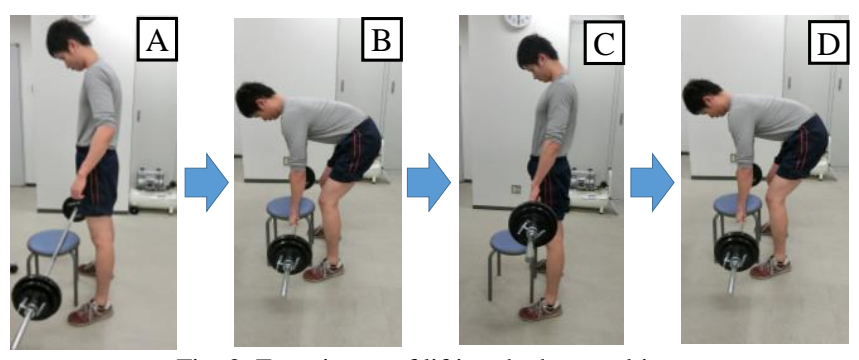

Fig. 3. Experiment of lifting the heavy object.

In the experiment, the compressed air was supplied to the artificial muscles when the subject started to lift the heavy object after around 4 seconds from the experiment start. Then, the compressed air was kept supplying while the subject was maintaining the heavy object lifted in State C. Finally, the compressed air was released from the artificial muscles immediately before the subject takes down the heavy object.

The measurement part of SEMG was chosen as the erector spinae muscle which is used when lifting the heavy object, and the electrodes of the electromyograph were attached on the position shown in Fig. 4.

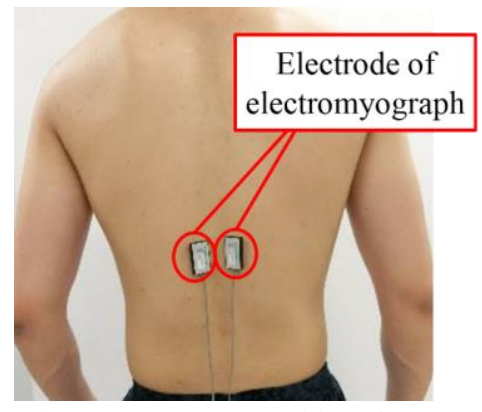

Fig. 4. Measurement position of SEMG.

\section{2) Experiment of transferring the heavy object by turning around}

Along the 4 steps shown in Fig. 5, the subject lifted the
$20 \mathrm{~kg}$ heavy object and took down the heavy object after turning around to the left in 8 seconds. State A is the initial posture where the subject stood in front of the heavy object and held it. State B is the state where the subject lifted the heavy object after 1 second from the experiment start. State C is the state where the subject turned around to the left with the heavy object lifted after around 2 to 5 seconds from the experiment start. State D is the state where the subject took down the heavy object after around 5 to 8 seconds from the experiment start.
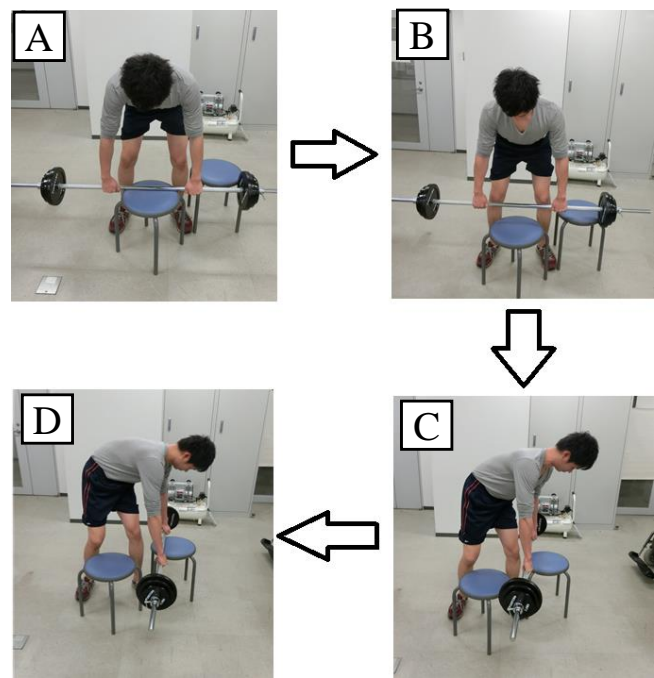

Fig. 5. Experiment of transferring the heavy object

In the experiment, the compressed air was supplied to the artificial muscles when the subject started to lift the heavy object after around 1 second from the experiment start. Then, the compressed air was kept suppliying while the subject was turning around to the left with the heavy object lifted. Finally, after turning around was completed, the heavy object was taken down slowly with releasing the compressed air from the artificial muscles.

The measurement part of SEMG was chosen as the obliquus externus abdominis muscle which is used when transferring the lifted heavy object by turning around, and the electrodes of the electromyograph were attached on the position shown in Fig. 6.

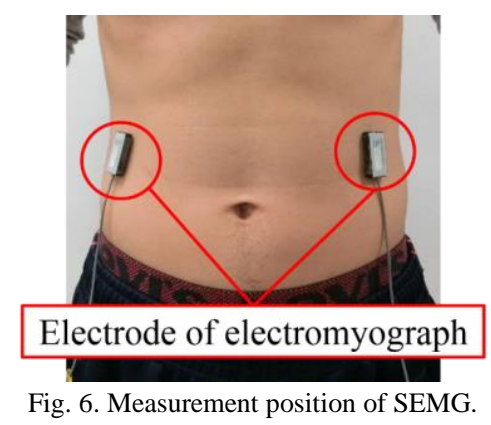

\section{Results}

\section{3) Experiment of lifting the heavy object}

Experimental result is shown in Fig. 7. The peak of the IEMG is seen at around 4 to 5 seconds. At this time the subject was lifting the heavy object. The peak value of the 
IEMG at 4 to 5 seconds in the case of wearing the knee pad type assist suit (Cool Vest) decreased $30 \%$ at the maximum as compared with the case of un-wearing the assist suit.

In addition, the increase of the IEMG is seen at around 7 to 9 seconds. At this time the subject was taking down the heavy object. Also in this case, the peak value of the IEMG at 7 to 9 seconds in the case of wearing the knee pad type assist suit decreased $46 \%$ at the maximum as compared with the case of un-wearing the assist suit. This is caused by the following reason. The air in the artificial muscle is not released momentarily, but is released slowly taking about 3 seconds. Therefore, it is considered that the assist suit assists the wearer even in the case of taking down the heavy object.

Moreover, from Fig. 7, it was confirmed that the same degree of the IEMG was observed in both wearing the knee pad type assist suit and wearing the overalls type assist suit developed in previous study. Therefore, it is considered that the assist effect of the knee pad type assist suit is the same degree as that of the overalls type assist suit. From the above results, the assist effect of the developed assist suit, Cool Vest, was verified.

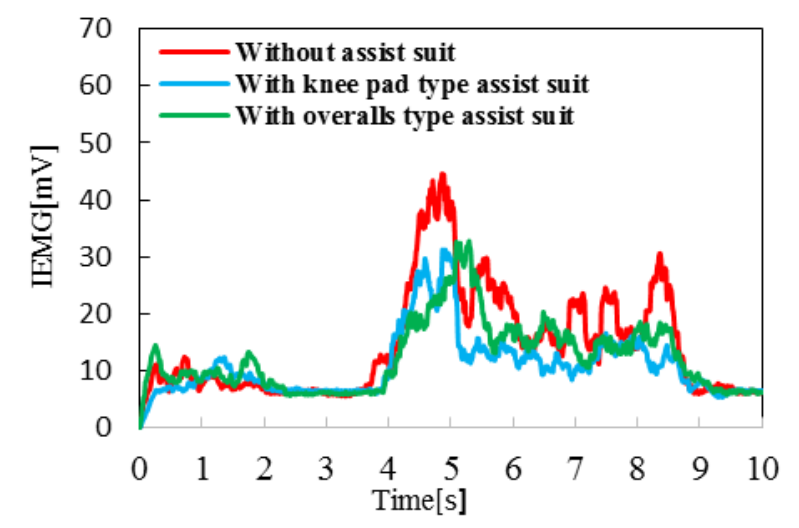

Fig. 7. Experimental result for lifting the heavy object.

\section{4) Experiment of transferring the heavy object by turning around}

Experimental result of the right obliquus externus abdominis muscle is shown in Fig. 8. Under wearing the knee pad type assist suit and un-wearing the assist suit, the difference of the IEMG is not seen at around 0 to 5 seconds while the subject was lifting the heavy object and turning around to the left. On the other hand, the increase of the IEMG in the right obliquus externus abdominis muscle is seen at around 5 to 7 seconds while the subject was taking down the heavy object. The peak value of the IEMG at 5 to 7 seconds in the case of wearing the knee pad type assist suit decreased $43 \%$ at the maximum as compared with the case of un-wearing the assist suit.

This is caused by the following reason. In general, the muscles used for lifting the heavy object are mainly erector spinae muscles, and burdens of obliquus externus abdominis muscles are comparatively few. On the other hand, when the upper body is twisted, the obliquus externus abdominis muscle receives a big burden. Since the subject takes down the heavy object slowly with keeping his upper body twisted on the left, the burden is applied to his right obliquus externus abdominis muscle. The burden applied to the right obliquus externus abdominis muscle was reduced by the contractile force of the artificial muscle in the assist suit. Thus, it was confirmed that by wearing the Cool Vest, the assist effect is obtained also in the case of taking down the heavy object with the upper body twisted.

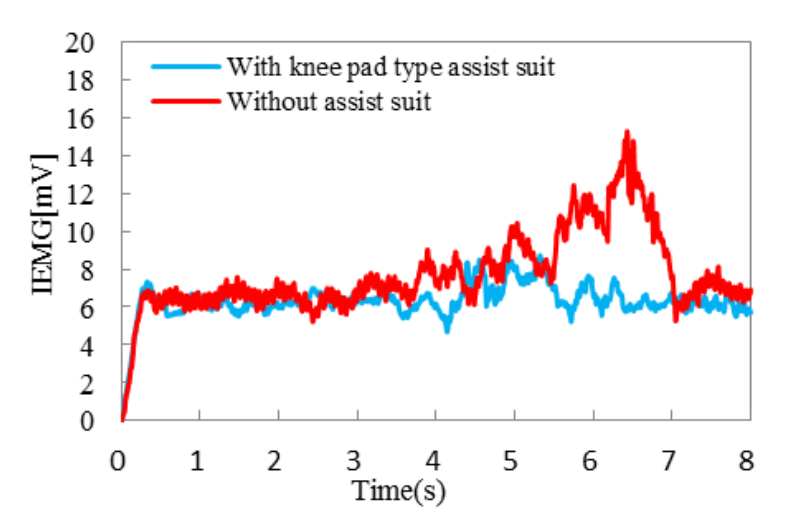

Fig. 8. Experimental result for transferring the heavy object.

\section{IMPROVEMENT OF AIR SUPPLY METHOD}

In our previously developed assist suit, air compressor was used to supply the compressed air to the artificial muscles. However, in this case, caregiver's area of activity is restricted because the assist suit must be connected to the compressor by air tube. In order to solve this problem, two air tanks were attached to the assist suit, and the compressed air is supplied to the artificial muscles from the air tanks filled with the compressed air. As shown in Fig. 9, two air tanks with each capacity of $750 \mathrm{ml}$ were attached to the wearer's waist using the bottle holder.

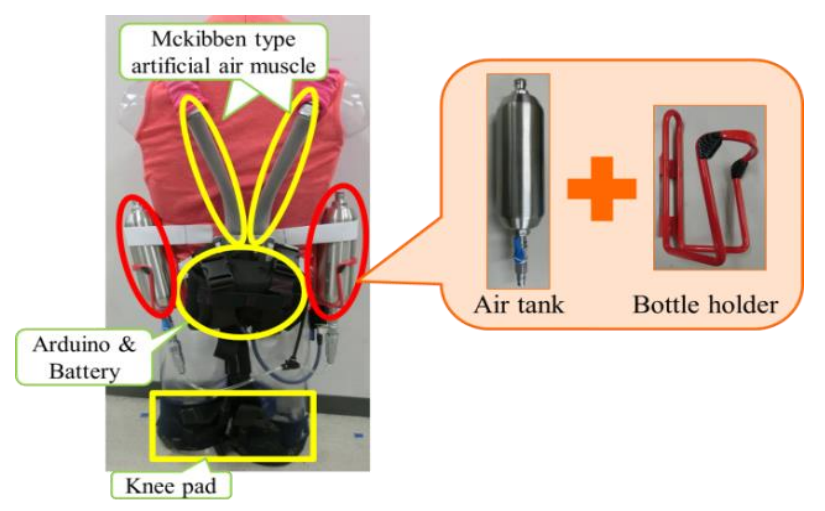

Fig. 9. Attachment of air tank to cool vest.

In this case, caregiver's area of activity is expanded, but the number of times which can be used for assisting the transfer work is restricted since capacity of the air tank is limited. If air tank with large capacity is used, it is possible to increase the number of times for assistance, however gross weight of the assist suit becomes heavy.

The supply pressure of the compressed air for S-size and L-size artificial muscles is shown in Table II. In S-size assist suit two S-size artificial muscles are used, and in L-size assist suit two L-size artificial muscles are used. In addition, define "assistable times" as the maximum number of times which can be used for assisting the transfer work in fixed assist force by fullness of 1 time of the compressed air to the air tanks. The 
assistable times for S-size and L-size assist suits is also shown in Table II.

In order to increase the assistable times in the assist suit for nursing care, the following two methods were proposed as air supplying system to the artificial muscle.

\begin{tabular}{|c|c||c|c|}
\hline \multicolumn{1}{|c|}{ TABLE II: SUPPL PRESSURE AND ASSISTABLE TIMES } \\
\hline & $\begin{array}{c}\text { Supply } \\
\text { pressure }\end{array}$ & $\begin{array}{c}\text { Assistable } \\
\text { times }\end{array}$ \\
\hline $\begin{array}{c}\text { S-size Artificial } \\
\text { muscle }\end{array}$ & $0.3 \mathrm{MPa}$ & $\begin{array}{c}\text { S-size Assist } \\
\text { suit }\end{array}$ & 5 \\
\hline $\begin{array}{c}\text { L-size Artificial } \\
\text { muscle }\end{array}$ & $0.5 \mathrm{MPa}$ & $\begin{array}{c}\text { L-size Assist } \\
\text { suit }\end{array}$ & 3 \\
\hline
\end{tabular}

\section{A. Air Recycling System}

Structure and overview of the proposed air recycling system is shown in Fig. 10. In the previous assist suit, the compressed air supplied to the artificial muscle was discharged to the outside directly. The proposed air recycling system is a system which reuses the air discharged.

As shown in Fig. 10, the sub-air tank for storing the discharged air was attached to the air exit. In this study, another artificial muscle was used as the sub-air tank. When discharging the air from the artificial muscle, first the discharged air is stored in the sub-air tank. Then, the air remained in the artificial muscle, which cannot be stored in the sub-air tank, is discharged to the outside through another air exit.
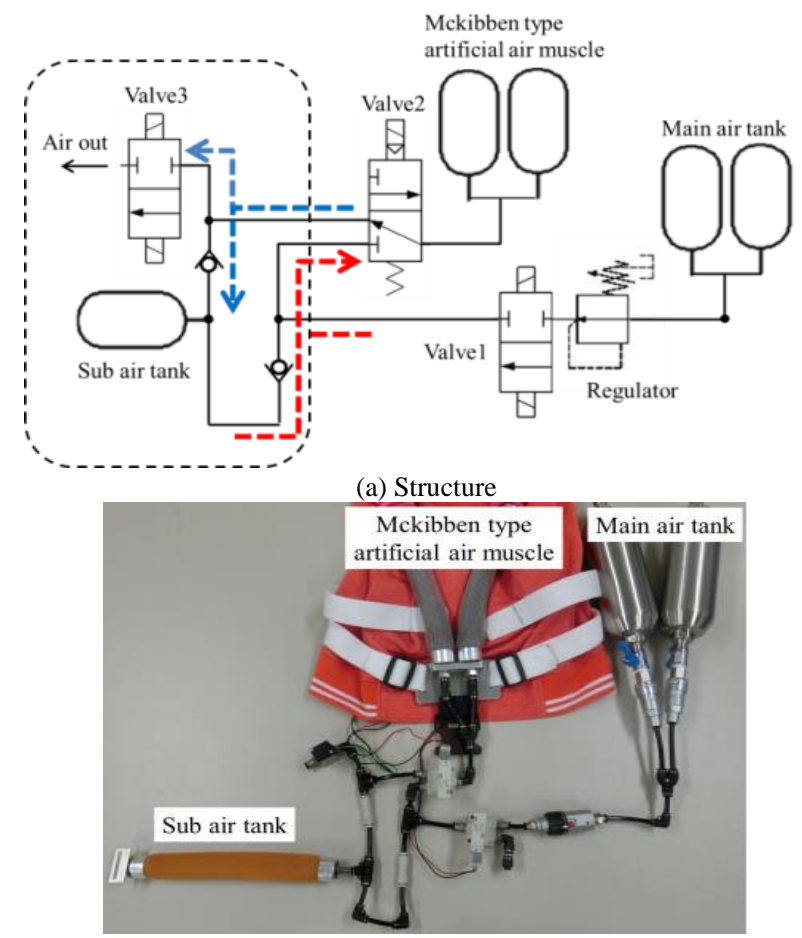

(b) Overview

Fig. 10. Air recycling system.

When shrinking the artificial muscle again, the compressed air stored in the sub-air tank is supplied to the artificial muscle first, and then, after 0.2 to 0.3 seconds the compressed air in the main air tanks is supplied to the artificial muscle. Thus, the compressed air stored in the main air tanks is saved. In addition, in order to prevent the counter-flow of the air, non-return valve is attached between the air exit and the sub-air tank, and between the main air tanks and the sub-air tank.

\section{B. Air Generation System}

Structure and overview of the proposed air generation system is shown in Fig. 11. The proposed air generation system is a system which equips a small air compressor MP-2-C made by SQUSE Inc., and self-generates a part of the compressed air by the small compressor. In this system, the inside pressure of the sub-air tank is measured by the sensor, and the compressed air is accumulated in the sub-air tank using the small compressor so that the inside pressure of the sub-air tank always keeps a fixed value $0.3 \mathrm{MPa}$.

As shown in Fig. 11, the sub-air tank for storing the generated compressed air was attached to the air exit. In this study, another artificial muscle was used as the sub-air tank. When shrinking the artificial muscle, the compressed air stored in the sub-air tank is supplied to the artificial muscle first, and then, after 0.2 to 0.3 seconds the compressed air in the main air tanks is supplied to the artificial muscle. Thus, the compressed air stored in the main air tanks is saved.

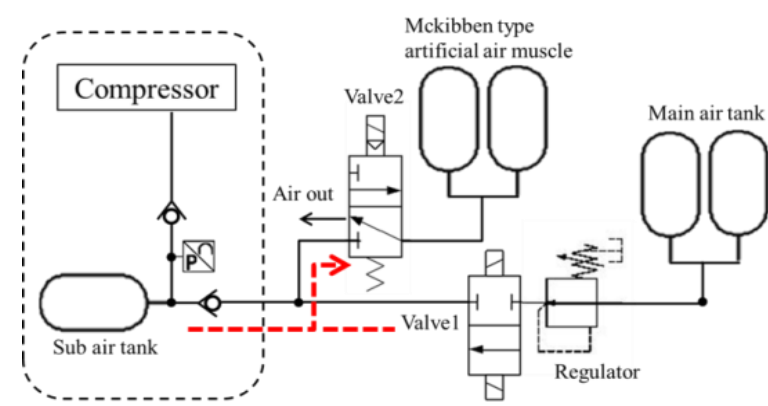

(a) Structure

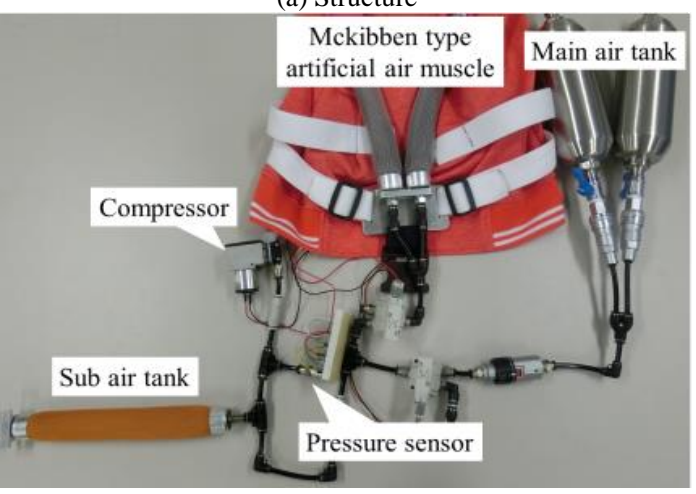

(b) Overview

Fig. 11. Air generation system.

\section{Evaluation Experiments}

\section{1) Experimental method}

Using the proposed two air supplying systems, supply and discharge of the compressed air to the artificial muscle were performed repeatedly. Then, the inside pressure of the artificial muscle at the time of supply of the compressed air was measured.

In this experiment, S-size assist suit was chosen as the experimental subject. The value of the supply pressure of the compressed air to two artificial muscles (each 280mm length) in the assist suit was set to $0.3 \mathrm{MPa}$. The measurements were started from the state where the compressed air of $0.9 \mathrm{MPa}$ 
was already accumulated in the two main air tanks (each $750 \mathrm{ml}$ of capacity) and the compressed air of $0.5 \mathrm{MPa}$ was already accumulated in the sub-air tank (which is another artificial muscle of $330 \mathrm{~mm}$ length). In addition, the measurement using the previous system was also conducted for comparison.

\section{2) Results}

Experimental result is shown in Fig. 12. In this assist suit, when the pressure of the compressed air supplied to the artificial muscle declines rapidly, wearer can no longer feel the assist effect. Therefore, the number of measurement times before the inside pressure of the artificial muscle decreased more than $0.05 \mathrm{MPa}$ rapidly is regarded as the assistable times.

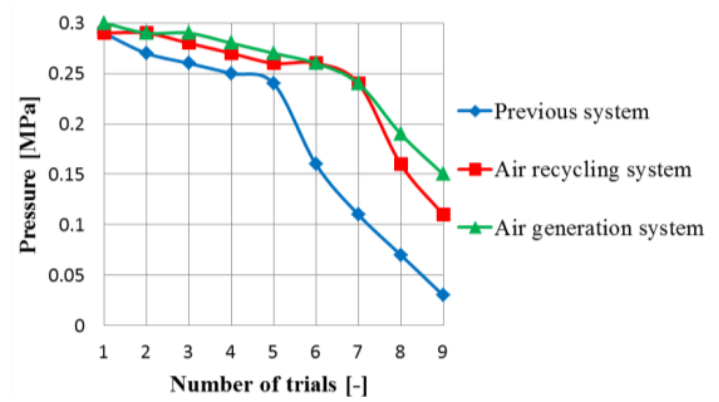

Fig. 12. Measurement results of inside pressure of artificial muscle.

From Fig. 12, in the case of the previous system, since the inside pressure of the artificial muscle decreased rapidly at the 6th measurement, it can be said that the assistable times is 5 times. By using the air recycling system and the air generation system, the assistable times was extended to 7 times, respectively. Therefore, we succeeded in increasing the number of times which can be used for assisting the transfer work compared with the previous system.

\section{CONCLUSIONS}

In this paper, the knee pad type power assist suit was developed so as to improve the problem of the overalls type power assist suit developed in our previous study. Verification experiments assuming the transfer work in nursing care were carried out and the assist effect was evaluated using the integrated electromyogram. Then, by wearing the developed assist suit, it was confirmed that the burden of the erector spinae muscle decreased in the case of lifting the heavy object and the burden of the obliquus externus abdominis muscle decreased in the case of transferring the heavy object by turning around.

In addition, air supplying method to the artificial muscle was improved to increase the number of times which can be used for assistance. The air recycling system and the air generation system were proposed, and evaluation experiments were executed. As results, the number of times which can be used for assisting the transfer work increased from 5 times to 7 times by using these air supplying systems.

The developed assist suit for nursing care has characteristics of being light weight, inexpensive, high flexibility, and easy to put on and take off. Therefore, the developed assist suit meets the needs in the field of nursing care.

\section{ACKNOWLEDGMENT}

The authors wish to thank Mr. Toshihiko Kobayashi and Mr. Tomohiro Ooki for their cooperation to the experiments.

\section{REFERENCES}

[1] K. Kasaoka and Y. Sankai, "Predictive control estimating operator's intention for stepping-up motion by exo-sckeleton type power assis system Hal," in Proc. 2001 lEEE/RSJ International Conference On Intelligent Robots and Systems, Maui, Hawaii, USA, 2001, pp. 1578-1583.

[2] Exoskeleton Report AWN-03. [Online]. Available: https://exoskeletonreport.com/product/awn-03/

[3] H. Kobayashi, Y. Ishida, and H. Suzuki, "Realization of all motion for the upper limb by a muscle suit," in Proc. 2004 IEEE International Workshop on Robot and Human Interactive Communication, Kurashiki, Okayama, Japan, 2004, pp. 631-636.

[4] K. Yamamoto, K. Hyodo, M. Ishii, and T. Matsuo, "Development of power assisting suit for assisting nurse labor," JSME International Journal, Series C, vol. 45, no. 3, 2001, pp. 703-711.

[5] Ekso bionics. [Online]. Available: https://eksobionics.com/eksoworks/

[6] Smart exoskeletons for an industry in motion. [Online]. Available: http://www.germanbionic.com/

[7] Hyundai motor group ventures further into new robotics industry. [Online]. Available: https://www.hyundai.news/uk/brand/hyundai-motor-group-ventures-f urther-into-new-robotics-industry/

[8] H. Inose, S. Mohri, H. Arakawa, M. Okui, K. Koide, Y. Yamada, I. Kikutani, and T. Nakamura, "Semi-endoskeleton-type waist assist AB-wear suit equipped with compressive force reduction mechanism," in Proc. 2017 IEEE International Conference on Robotics and Automation, Singapore, 2017, pp. 6014-6019.

[9] D. Sasaki and M. Takaiwa, "Development of pneumatic power assist wear to reduce physical burden," in Proc. of the 2014 IEEE/SICE International Symposium on System Integration, Tokyo, Japan, 2014, pp. 626-632.

[10] Y. Imamura, T. Tanaka, Y. Suzuki, K. Takizawa, and M. Yamanaka, "Motion-based design of elastic belts for passive assistive device using musculoskeletal model," in Proc. 2011 IEEE International Conference on Robotics and Biomimetics, Phuket, Thailand, 2011, pp. 1343-1348.

[11] C. Ishii, H. Yamamoto, and D. Takigawa, "Development of a new type of lightweight power assist suit for transfer work," in Proc. 2015 Asia-Pacific Conference on Computer Aided System Engineering, 2015, pp. 208-213.

[12] M. Okui, Y. Nagura, Y. Yamada, and T. Nakamura, "Hybrid pneumatic source based on evaluation of air compression methods for portability," IEEE Robotics and Automation Letters, vol. 3, no. 2, April 2018, pp.819-826.

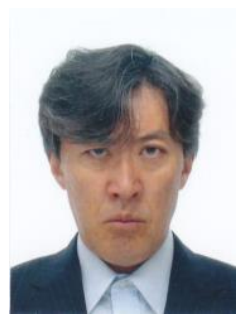

Chiharu Ishii received his $\mathrm{PhD}$ in mechanical engineering from Sophia University, Japan in 1997. From 2002 to 2009, he was an assistant professor with Kogakuin University. Currently, he is a professor at the Department of Mechanical Engineering, Hosei University, Japan. His research interests are in medical robotics, assistive technology and robust control. He is a member of IEEE, SICE, JSME, RSJ, IEEJ and JSCAS.

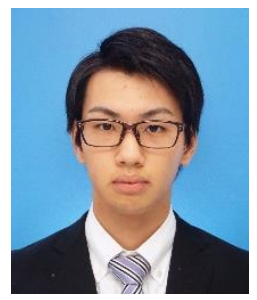

Kotaro Yoshida received his BE in mechanical engineering from Hosei University, Japan in 2017. Currently, he is a master course student at Graduate School of Engineering, Hosei University, Japan. His research interest is in assistive technology. 